\title{
A theoretical view on concept mapping
}

\author{
Ray McAleese
}

Heriot-Watt University, UK

\begin{abstract}
Auto-monitoring is the pivotal concept in understanding the operation of concept maps, which have been used to help learners make sense of their study and plan learning activities.

Central to auto-monitoring is the idea of a 'learning arena' where individuals can manipulate concept representations and engage in the processes of checking, resolving and confirming. understandings. The learner is assisted by familiar metaphors (for example, networks) and the possibility of thinking 'on action' while 'in action'. This paper discusses these concepts, and concludes by arguing that maps are part of the process of learning rather than a manifestation of learning itself. Auto-monitoring is suggested as an appropriate term to describe the process of engaging in the learning arena.
\end{abstract}

'It is in these shimmering and incessant embraces that the infinite patterns, the infinite Maps of the Mind, are created, nurtured and grown. Radiant Thinking reflects your internal structure and processes. The Mind Map is your external mirror of your own Radiant Thinking and allows you to access this vast thinking powerhouse.' Tony Buzan (1993).

\section{Definition}

Auto-monitoring is a technique of personal or group knowledge-presentation and re-presentation. Such techniques are often supported by computer applications that make graphical representations of knowledge structures. This process is at the core of what is called concept mapping.

\section{Context and background}

Learning technology comprises a collection of pragmatic and theoretical positions on the way learners come to know and teachers provide the appropriate experiences. At its core is a developing design philosophy that uses instructional design theory or educational technology. Within learning technology is an interest in what some might call content free courseware or Mindtools (Kommers 1992). The idea of using concept maps (Novak and Gowin 1984) or mind maps (Buzan 1993) as part of an instructional strategy is not new (Bogden 1977; 
Reader and Hammond 1993), but it is timely to consider the contribution that such techniques have made to learning technology. This paper sets out a theoretical base for thinking about concept maps. Earlier attempts have suggested some elements in the process (Deikhoff 1982; Gold 1984; McAleese 1985; McAleese 1987; McAleese 1990; McAleese 1992). The principal idea behind such tools is that of auto-monitoring - the ability of learners to develop thinking skills. The term auto-monitoring ( $\mathrm{A} / \mathrm{M})$ will be used here to encompass components of Mindtools, mind maps, concept mapping, thinking skills, and so on.

Before directly addressing the theory behind $\mathrm{A} / \mathrm{M}$, however, it will be useful to take as a springboard the current debate in higher education. The main strand to this background is the need for students to acquire study skills. The need for better leaming and study skills in a significant sector of the student population is identified in the Howie Report (1992), the MacFarlane Report (1993), the Edinburgh University CRLI Report on the Transition from School to Higher Education in Scotland (Wall et al 1991) and the Report of the National Commission on Education (Learning to Succeed 1993). All these sources identify the need for students in higher education to be able to think and to develop critical thinking skills.

\section{Cognitive tools}

A realistic starting point is what has been called situated cognition (Brown et al 1989) The most useful contribution is the claim that concepts are both situated and progressively developed through activity. Knowledge is claimed to be like tools, and thinking occurs when the tools are used for some task. Brown et al (1989) and Carroll (1989), along with many others, provide a stable raft of research supporting the idea of conceptual tools. A/M is the executive control and operation of such tools (for example, Clancey 1993). Not everyone is convinced that there are practical applications for situated cognition, but it does provide a scaffolding for the argument (Hoppe 1993). A/M is the craft that the apprentice is acquiring in formal and informal education. That is, the learner is acquiring the skills needed to operate with and on concepts. Some would argue that this is also the function of language, namely a means by which learners can operate on concepts. Learning, seen in this way, is the outcome of learner activity. It is something learners cause by their actions: leaming is a process of re-constructing and re-presenting what is known (Arzi and West 1986). A/M is therefore based on a set of assumptions and procedures that allow learners to be and to become responsible for their own learning. Learning is seen as being something that occurs as a result of student/learner activities.

\section{An A/M model for concept mapping}

Figures 1 and 2 indicate the main components and suggest their interdependencies.

The learner is engaged in a cognitively active process in an environment that supports the manipulation of knowledge artefacts: ideas, concepts etc. The general process can be called engagement. The learning arena is the virtual space where operations on entities occur. In this space, the learner is able to engage with representations of information, ideas and concepts. This is a type of rhetorical space (Scardamelia and Bereiter 1987). It is not constrained except with the application of a cognitive template (see Streitz and Hammeman 1990). The engagement occurs at two levels. First, the operational level where the computer interface allows nodes to be moved, nodes created, etc. Secondly, the cognitive level where thinking occurs. In general thinking precedes operations; however, operations will precipitate thinking, and there 


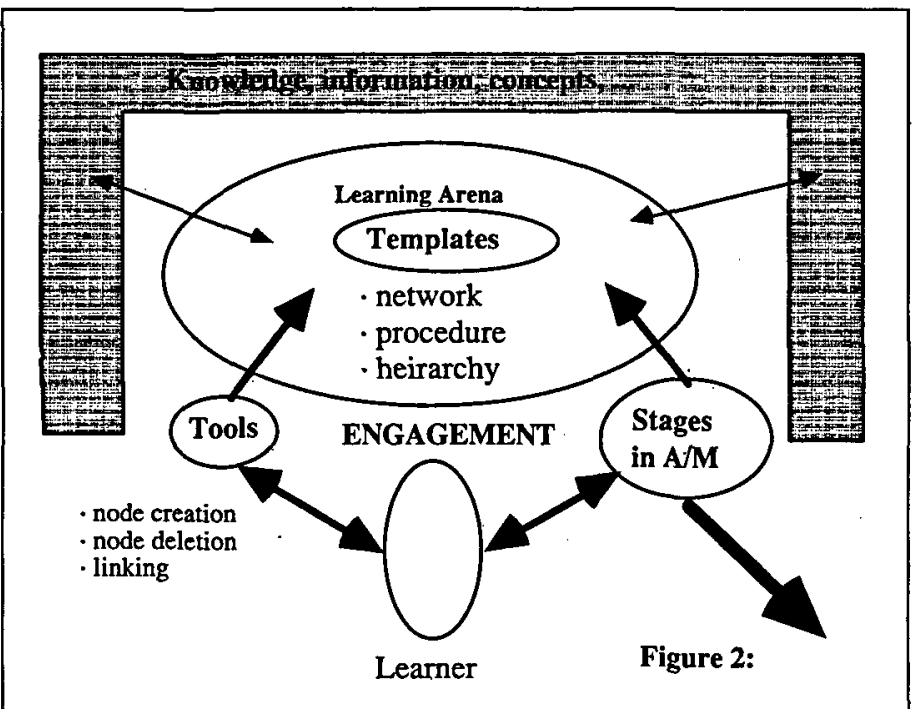

Figure 1: The learning arena - auto-monitoring $(A / M)$

is therefore a cybernetic system in operation. In addition, the learners can assess previous understandings. This accession is dynamic - that is, it occurs while operations are on-going in 'the arena. Ideas are created on the fly, concepts are recalled when appropriate, and so forth. The learner has tools to use and operates through a series of stages (Figure 2), though the stages, while explicit and sequential in terms of the operations, need not necessarily be followed. Acknowledgement is the state of initial awareness: the learner thinks about some concept.

Representation is the formal activity allowed by the tools (for example, concept label creation). Viewing is the core activity of being perceptually aware of the entities in the learning arena. There is a loop between representation and viewing. Checking is a process whereby concept labels are compared, link values are scrutinized, and the learner attempts to make sense of the nodes, links, etc. Resolution is required when conflicts occur in labelling or linking. The processes of viewing, checking and resolving operate a loop. Confirming in-

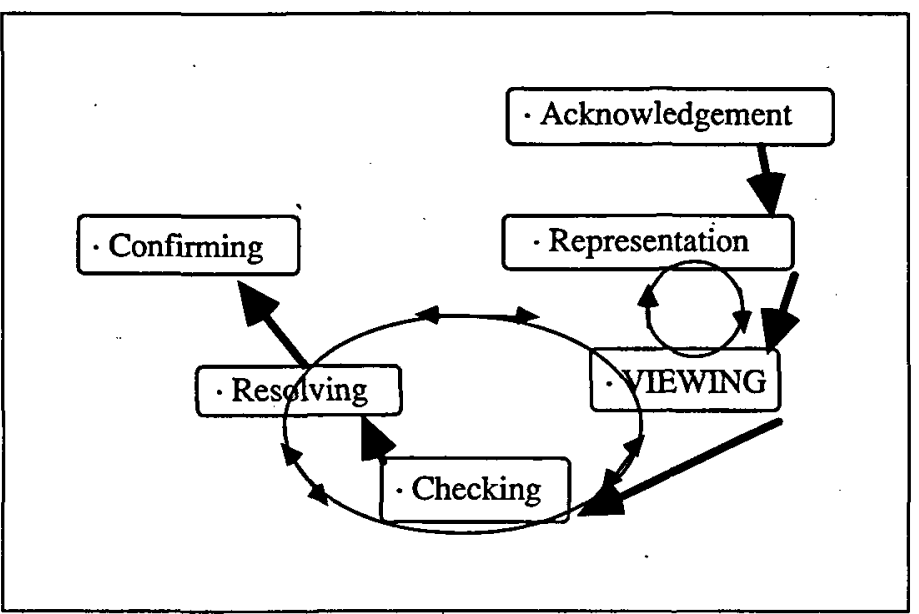

Figure 2: The stages of $A / M$ 
volves operations such as agreeing that the representation is what was intended and has no inconsistencies. Confirming is a form of commitment (see below).

In addition, the leamer has available a number of templates that constrain the operations performed. In general, the principal template is the net, consisting of nodes and links. Conceptually the net is n-dimensional. The tools are the computer-related operations using a WIMP (graphical) interface. Tools will change with the instantiation of different templates. In general, tools will allow representation of elements of templates to be manipulated. For example, nodes can be moved, created, deleted, and the like. Although the net is the most popular template, the outline or constrained net is also useful. The outline is a hierarchy, and the freedom to manipulate concepts is pre-determined by an [is-a] relation:

$$
\text { (B - is-a - A } \rightarrow \text { B has attributes of A) }
$$

Processes are cognitive operations that operate on their own or in concert with engagement. Processes are dependent on the template selected. For example, in a hierarchy template there is an inheritance influence on the operations. Dependencies are created and attribute effects are transmitted through the underlying structure.

\section{An operational definition of $A / M$ in concept maps}

Learners represent concepts, and in so doing make propositions. Kathleen Fisher calls these propositions instances in SemNet - Semantic Net (Fisher et al 1990). Here ambiguities arise, propositions suggest other propositions, and elements in the propositions need disambiguation - that is, differentiating and integrating. The learner will experience dissonance and will have to make commitments. This state leads to a heightened awareness of what is known and what is not (McAleese 1985). Tacit or ill-remembered ideas are exteriorized through engagement with represented propositions (Pask 1984). The acquisition of knowledge (that is, the outcome of activities) is a negotiated state. Meaning is negotiated by resolving and making explicit concepts, their attributes, etc. (Moyse 1991).

Figure 3: Activities, processes and visualisation

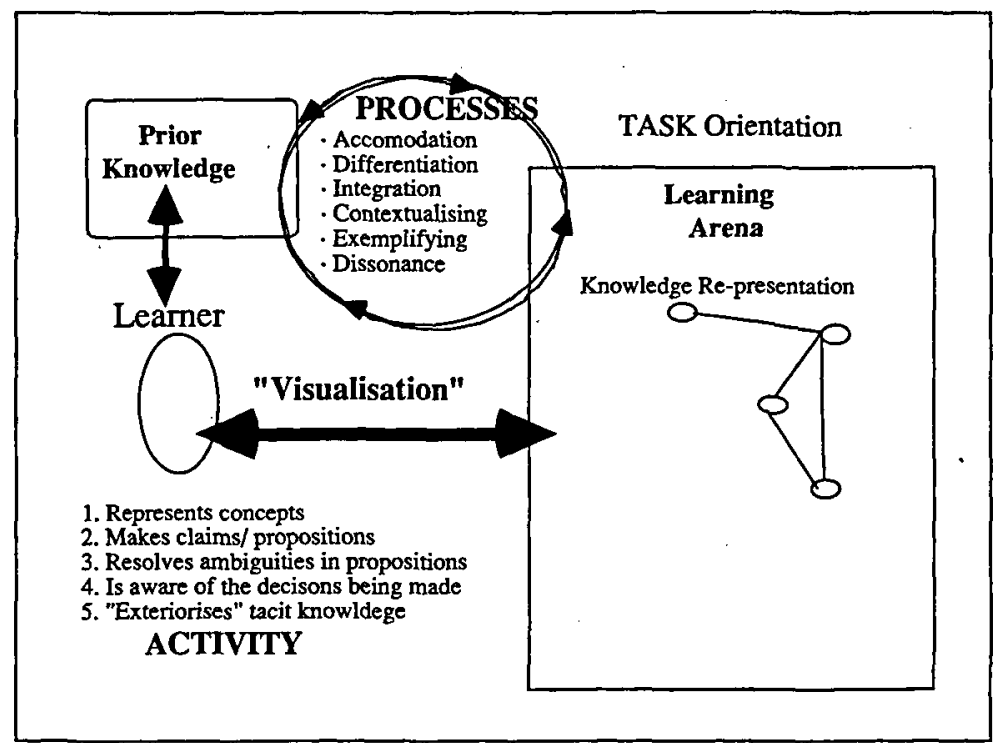


This activity is operationalized in the WIMP interface. Mouse movement indicates, but does not determine, point of view (Fairchild 1993); node creation (involving several sub-actions depending on the $\mathrm{A} / \mathrm{M}$ application) indicates the exteriorization of a propositional element; linking nodes indicates the explication of the proposition. Nodes are represented by an implicit semantic distance (Holley and Dansereau 1988). The processes at work are general cognitive processes of accommodation, differentiation, etc. The computer's role is to manage the activities and to provide a virtual learning arena where actions and intentions can be seen, recorded and if necessary replayed. The computer, while not essential to $A / M$, is thus a powerful adjunct in the supportive learning environment.

A key aspect of $A / M$ is visualization. While a graphical representation is not necessary for $\mathrm{A} / \mathrm{M}$ to occur, it does seem that the ability to see the results of thinking has a strong effect on the process. Work by Piagetian thinkers suggests that the concrete portrayal of abstract, illconceived ideas is an important precursor to problem solving. There is compelling evidence from research in information management that graphical metaphors facilitate the specification of intent and the presentation of choices. Indeed, work on degrees of interest, for example fish-eye viewers, suggests that data-presentation techniques are not only important in handling large numbers of nodes and relationships, but also allow learners to make use of different perspectives on the same data set concurrently (Fairchild 1993). Figure 3 provides further explanation.

\section{Visualization and the problem of scale}

The above model suggests an over-arching process of visualization to encompass the process by which learners make sense of the web of interconnected concept labels. As long as the learning arena is a bounded 2-dimensional area, the problem of too many concepts does not arise. However, sooner or later learners create many nodes and wish to make many associations. The problem of visualizing large semantic spaces has been tackled by MCC (Microelectronics and Computer Technology Corporation) with their work on SemNet (the name is the same as that used by Kathleen Fisher for her SemNet, based on Novak et al, referred to previously). SemNet research at MCC suggests that in visualization, three states for learners are important:

- they must be able to identify (see) individual concept labels;

- the relative positions of concept labels must be obvious in the semantic space (the learning arena);

- learners must be able easily to detect relationships between concept labels.

In addition, learners must be able to make sense of the dimensions of the space. A learning arena portrayed on a computer screen is confined by the 2-dimensional window. Judicious use of overviews and fish-eye views can make the space more extensive. SemNet by MCC used the idea of point-of-view very effectively to reduce complexity and to show, at the same time, the relevant nodes. In general, the 2-dimensional space is concerned only with semantic closeness. Learners can place concept labels as closely or as remotely as they choose. The meaning of the location is known only to the individual who creates the network. I have suggested that two views are of particular value: terrain views and street views (McAleese 1983). In the former, the learner is able to see the extent and context of knowledge propositions. In the latter, the learner sees the detail and relative interdependencies. 


\section{Backing and warrant}

The main problem is that $\mathrm{A} / \mathrm{M}$ is such a universal concept that it draws on a wide range of developed areas of understanding. Therefore, the number of related ideas that contribute to the thinking on $\mathrm{A} / \mathrm{M}$ is open to debate and question. The influences on $\mathrm{A} / \mathrm{M}$ range from constructivist positions explaining the way learners make sense, to normative positions that argue for active reflective learners who debate and evaluate data with a degree of rigour. The tension between a description of 'how it is ' and a description of 'how it should be' is not unique to $\mathrm{A} / \mathrm{M}$. The key result influences are concept mapping, meta-cognition, and reflective practice, though these areas are not mutually exclusive.

\section{Concept mapping - key points}

The technique is usually associated in this context with Joseph Novak (Novak and Gowin 1984). Concept maps represent meaningful relationships between entities (concepts) in the form of propositions. A proposition is two or more concept labels linked by a labelled relationship in a semantic unit (see also Fisher et al 1990 for her work on SemNet). A concept map, according to Novak and other 'mappers' is a technique for externalizing concept labels and propositions created by concept labels and relationships. The key points are as follows.

- Meaningful relationships - the representations make sense to the learner. They may or may not be true - it is possible to have a raft of untrue meaningful relationships. Indeed, many learners do have such entities, especially in their understanding of basic science.

- Concept labels - the representation is a label or a sign for something that is signified. Therefore, the sign $\{\mathrm{mol} \mathrm{e} \mathrm{cu} \mathrm{le}\}$ is a sign for a chemical entity that consists of atoms held together and acting in a specified way.

- Propositions - the meaningful units make sense according to the learner. Therefore, ' isomers\} have [n different forms\}' is a proposition created by two concept labels and one relationship. In this case, the relationship is of special form - it indicates an attribute of the first concept (see McAleese 1990 for a more detailed view of the syntax of such propositions).

\section{The mind map and flowscape}

Many other authors have contributed to the understanding of concept maps, most notably Tony Buzan (mind maps), and recently Edward de Bono (flowscapes).

The mind map (Buzan 1993) is a formalized procedure for using associations to create a pictorial representation of one or more ideas. The technique relies on brain-storming. The precise mapping between cortical function and the neuro-physiology of brain cells to bitmaps and 'clickable objects' on a computer screen remains uncertain. It is very tempting to say the mind map - or other concept map - can be isomorphic with 'understandings' as they are or must be, in the brain. Not even Buzan or de Bono would go that far, yet the metaphor is very apt, and Buzan's lucid writing makes many learners perform more effectively by providing a plausible study technique. Learners do seem to improve their overall performance in independent tests when they have 'sorted out their thinking' using a mind map. De Bono, using the flowscape (De Bono 1993), takes a very similar approach to Buzan. He has deeper roots in Piaget, but the technique of brain-storming creates the network or flowscape. 
De Bono takes the argument further by insisting that it is the dynamic nature of the interconnections that creates what he likes to call water logic. That is, a dynamic form of associations which is more concerned with what 'will happen' or 'becomes', than what 'is'. An important feature of the flowscape is the identification of clusters of concepts that are or become interdependent. They form loops, and de Bono uses such ideas in a diagnostic fashion to help learners identify key areas of thinking.

\section{Good or bad maps?}

Many workers have tried to score or evaluate maps. In particular, Novak has suggested, along with Gowin, two methods of scoring or formalizing thinking. Novak's technique is based on a detailed application of Ausubel (Novak and Gowin 1984). The degree of subsumption and differentiation, along with levels of differentiation, can be used to score a map once created. This technique does not address an ongoing evaluative function that may act as control over learners. Leamers can only use a post-production facility.

\section{The place of commitment}

Buzan and others suggest that there is an affective aspect to mapping. There has to be a commitment to the consequences of what is emerging. It is as if the creation of maps leads to a contract that the learner adopts. An idea that associates with this is cognitive dissonance (Festinger 1957). Cognitive dissonance is the state of mind that occurs when there is a tension between what should be and what is. Ideas conflict, and there is dissonance between concepts, positions and relationships that requires resolution. Often this happens when differentiation or integration occur. Two concepts are so similar that one label can be used to denote them. The association with Festinger is that cognitive dissonance involves not only cognitive attributes but affective attributes. In one sense, this is the tension between what ' $I$ think I know' and 'I can re-present what I know'.

Commitment to a re-presentation may be dangerous as it fixes the players and their positions. In essence, there is always going to be cognitive dissonance in $\mathrm{A} / \mathrm{M}$, as dissonance is a creative tension (see Dole and Niederhauser 1990). It drives the process by 'looking for' a state of rest or resolution. Dissonance is the cybernetic oil that makes the process work. Consequently, commitment to maps created during A/M is not necessary.

\section{Meta-cognition}

Meta-cognition generally refers to awareness of knowledge and an ability to comprehend, control and manipulate cognitive processes. The rather crude term helicoptering has been applied to the state in which learners can see their own conceptual terrain. They can rise above their understandings and explore their cognitive space as it is. This description seems very close to what is implied by auto-monitoring. The principal flaw here lies in the state of the conceptual terrain: the metaphor breaks down as the conceptual landscape does not necessarily exist prior to 'levitation'. A/M creates the terrain as well as providing a vehicle for viewing its topography. This distinction can be implied by that made by Buzan between 'note taking' and 'note making'. In the former, the terrain is almost complete; in the latter, the terrain is still evolving. Note making is rather akin to helicoptering above a volcanic eruption where the new terrain is still being formed. In a recent review, Osman and Hannifin (1992) suggest that the principal components for meta-cognition are: 
- meta-memory - knowledge and awareness of strategic behaviours and memory systems;

- meta-comprehension - the conscious process of knowing about comprehending and knowing how to comprehend;

- self-regulation - the continuous fine tuning by learners in response to and in the absence of knowledge of results concerning cognitive errors;

- schema training - the development of cognitive structures providing a framework for comprehension (schemas help learners generate perspectives that can be tested, reconciled and reconstructed with new engagements);

- transfer - the application of one set of procedures or skills to a different situation (transfer can be either vertical or lateral).

From the above conditions, it is apparent that meta-cognition is associated with reflective practice, to which I now turn.

\section{Reflective practice}

Reflective practice, according to Schön $(1983,1988)$, is the integration of thought and practice. It involves thinking critically and analysing actions, goals and activity. The reflective practitioner assumes the perspective of an external observer and speculates on how practice is effected (Kottkamp 1990; Osterman 1990; Peters 1991). According to Peters (1992), '[reflective practice] is a special kind of practice [...] that involves a systematic inquiry into the practice itself.'

Educators have become familiar with the concept of reflective practice through Schön's $(1983,1988)$ writings about reflective practitioners. Schön's work has a historical foundation in a tradition of learning supported by Dewey, Lewin and Piaget, each of whom advocated that learning is dependent on the integration of experience with reflection and of theory with practice. Although each argued that experience is the basis for learning, each also maintained that leaming cannot take place without reflection. In reflective practice, reflection is the essential part of the learning process because it results in making sense of or extracting meaning from the experience (Osterman 1990). For Schön (1988), the stage is set for reflection when 'knowing-in-action' - the sort of knowledge that professionals come to depend on to perform their work spontaneously - produces an unexpected outcome or surprise. This surprise can lead to one of two kinds of reflection: reflection on action, which occurs either following or by interrupting the activity, or reflection in action, which occurs during (without interrupting) the activity by thinking about how to re-shape the activity while it is under way (ERIC 1992).

Kottkamp (1990) uses the terms offline and online to distinguish between reflection-on-action and reflection-in-action: Reflection-on-action takes place after the activity (that is, offline), when full attention can be given to analysis without the necessity for immediate action and when there are opportunities for the professional to receive assistance from others. Reflectionin-action, which occurs during the event, may be more effective in improving practice.

\section{Conclusion}

This paper suggests a theoretical framework for auto-monitoring. Without some form of warrant to concept mapping, the development of applications will be driven by available 
technology, or what can be done rather than what is useful. The central argument is that a process entitled auto-monitoring exists which is best seen as a learning arena. In this arena, learners can be aware of and manipulate learning activities as if they were a form of Lego or Meccano. The outcome of such operations is called a concept map. Maps are not the purpose, but rather an artefact of a process by which learning occurs.

\section{Acknowledgements}

The thinking reported in this paper was supported by the Courseware for Learning Study Skills (CLASS) project as part of the TLTP (I) initiative. Partners in this work are the University of Strathclyde, Glasgow Caledonian University, and Glasgow University with Heriot-Watt University. I am particularly indebted to Cathy Gunn in ICBL (Institute for Computer Based Learning, Heriot-Watt University) and to my other colleagues on the project, Geir Granum and Mike Kibby, for helping me think about auto-monitoring and concept maps. The CLASS project has produced a PC-Windows Concept Mapping Tool. The ideas in this paper are not necessarily those of the project team.

\section{References}

Arzi, H.J. and West, L.H.T. (1986), 'Ausubel revisited: more insights from a seemingly exhausted source', paper presented at the AERA meeting, San Francisco.

Bogden, C.A.B. (1977), The Use of Concept Mapping for Instructional Design, MSc. thesis, Comell University.

Brookfield, S.D. (1988), Developing Critical Thinkers, San Francisco, Jossey-Bass.

Brown, J.S., Collins, A. and Duguid, P. (1989), 'Situated cognition and the culture of learning', Educational Researcher, 18, 1, 32-42.

Buzan, T. (1993), The Mind Map Book: Radiant Thinking - The Major Evolution in Human Thought, London, BBC Publications.

Carroll, J.B. (1989), 'The Carroll model - a 25 year retrospective and prospective view', Educational Researcher, 18, 1, 26-31.

Cervero, R.M. (1988), Effective Continuing Education for Professionals, San Francisco, Jossey-Bass.

Cervero, R.M. (1989), 'Becoming more effective in everyday practice' in Quigley, B.A. (ed), Fulfilling the Promise of Adult and Continuing Education-New Directions for Continuing Education, no. 44, San Francisco, Jossey-Bass.

Clancey, W.J. (1993), 'Guidon-Manage revisited: a socio-technical systems approach', Journal of Artificial Intelligence in Education, 4, 1, 5-34.

De Bono, E. (1993), Water Logic: the alternative to I Am Right, You Are Wrong, London, Viking Press.

Deikhoff, G.M. (1982), 'Cognitive maps as a way of presenting the dimensions of comparison within the history of Psychology', Teaching of Psychology, 9, 115-16.

Dole, J.A. and Niederhauser, D.S. (1990), 'Students' level of commitment to their naive conceptions and their conceptual change learning from texts' in Zutell, J. and McCormick, S. 
(eds), Literacy Theory and Research: Analysis from Multiple Paradigms, Chicago, National Reading Conference Inc., 303-10.

ERIC (1992), 'Reflective practice in adult education', ERIC Digest 122 (Imel, S.), ED346319 92.

Fairchild, K.M. (1993), 'Information management using virtual reality-based visualisations', in Wexelblat, A. (ed), Virtual Reality - Applications and Explorations, London, Academic Press.

Festinger, L. (1957), A Theory of Cognitive Dissonance, Stanford University Press.

Fisher, K.M., Faletti, J. and Quinn, C.N. (1990), Exploring Cognitive Learning with Semantic Networks, CRMSE, San Diego State University.

Gold, P.C. (1984), 'Cognitive mapping', Academic Therapy, 19, 277-84.

Holley, C.D. and Dansereau, D.F. (eds) (1988), Spatial Learning Strategies, New York, Academic Press.

Hoppe, H.U. (1993), 'Cognitive apprenticeship - the emperor's new method: a problematical reaction to the debate on situated cognition and cognitive apprenticeship', Journal of Artificial Intelligence in Education, 4, 1, 49-54.

Howie Report (1992), Upper Secondary Education in Scotland, SOED/HMSO.

Imel, S. (1989), 'Teaching adults: is it different?', ERIC Digest 82, Columbus (Ohio), ERIC Clearinghouse on Adult, Career, and Vocational Education, 305-495.

Kommers. P. (1992), 'Graph computation as an orientation device in extended and cyclic hypertext networks' in Jonassen, D.J. and Mandal, H. (eds), Designing Hypermedia for Learning, NATO series F: 67, Berlin, Springer Verlag.

Kottkamp, R.B. (1990), 'Means for facilitating reflection', Education and Urban Society 22, 2, 182-203.

Lasley, T. (1989), Editorial, Journal of Teacher Education, 40, 2.

Learning to Succeed (1993), Report of the National Commission on Education, London, Heinemann.

MacFarlane, A.G.J. (1993), Teaching and Learning in an Expanding Higher Education System, The Committee of Scottish University Principals.

McAleese, R. (1985), 'Some problems of knowledge representation in an authoring environment: exteriorisation, anomalous state meta-cognition and self-confrontation, Programmed Learning and Education Technology, 22, 4, 299-306.

McAleese, R. (1987), 'Design and authoring: a model of cognitive processes' in Mathias, $\mathrm{H}$. (ed), Aspects of Educational Technology XXI, London, Kogan Page.

McAleese, R. (1990), 'Concepts as hypertext nodes: the ability to learn while navigating through hypertext nets' in Jonassen, D.J. and Mandal, H. (eds), Designing Hypermedia for Learning, NATO series F: 67, Berlin, Springer Verlag.

McAleese, R. (1992), 'The acquisition and representation of domain specific knowledge using NoteCards' in Olivero, A., Hypermedia Courseware: Structures of Communication and Intelligent Help, NATO ASI Series F:92, Berlin, Springer Verlag. 
Mezirow, J. (1990) (ed), Fostering Critical Reflection in Adulthood, San Francisco, JosseyBass.

Moyse, R. (1991), 'Multiple viewpoints imply knowledge negotiation', Interactive Learning International 7, 1, 21-38.

Novak, J.D. and Godwin, D.B. (1984), Learning How to Learn, Cambridge, CUP.

Osman, M.E. and Hannifin, M.J. (1992), 'Meta-cognition research and theory: analysis and implications for instructional design', ET $R \& D, 40,2,83-99$.

Osterman, K.F. (1990), 'Reflective practice: a new agenda for education', Education and Urban Society, 22, 2, 133-52.

Pask. G. (1984), 'Review of conversation theory and a protologic (or protolanguage), Lp', Educational Communications and Technology Journal, 32, 1, 3-40.

Peters, J. (1992), 'Strategies for reflective practice. Professional development for educators of adults' in Brockett, R. (ed), New Directions for Adult and Continuing Education, no. 51, San Francisco, Jossey-Bass.

Reader W. and Hammond N. (1993), Computer Based Tools to Support Learning from Hypertext; Concept Mapping Tools and Beyond, Department of Psychology, University of York (Mineo).

Rose, A. (1992), 'Framing our experience: research notes on reflective practice', Adult Learning, 3, 4, 5.

Roth, R.A. (1989), 'Preparing the reflective practitioner: transforming the apprentice through the dialectic', Journal of Teacher Education, 40, 2, 31-35.

Scardamalia, M. and Bereiter, C. (1987), 'Knowledge telling and knowledge transforming in written composition' in Rosenberg, S. (ed), Advances in Applied Linguistics, 2, 142-75.

Schön, D. (1983), The Reflective Practitioner, New York, Basic Books.

Schön, D. (1988), Educating the Reflective Practitioner, San Francisco, Jossey-Bass.

Streitz, N. and Hanneman, J. (1990), 'Elaborating arguments: writing, learning and reasoning in a hypertext based environment for authoring' in Jonassen, D.J. and Mandal, H. (eds), Designing Hypermedia for Learning, NATO series F: 67, Berlin, Springer Verlag.

Wall, D., Macauley, C., Entwistle, D. and Entwistle, N. (1991), The Transition from School to Higher Education in Scotland, Centre for Research on Learning and Instruction, University of Edinburgh.

\section{Editorial note}

Ray McAleese's paper was sent to two referees: Nick Hammond and David Jonassen. Their comments (those of David Jonassen were finally written jointly with Rose Marra) proved sufficiently stimulating to warrant publication in their own right as replies to the ideas presented in the paper. They are therefore included here. 